SANTOS, A.L.Q. et al. Músculos da face lateral e medial da pelve e da coxa de Coendou prehensilis (Linnaeus, 1758) (Rodentia, Erethizontidae). PUBVET, Londrina, V. 5, N. 20, Ed. 167, Art. 1125, 2011.

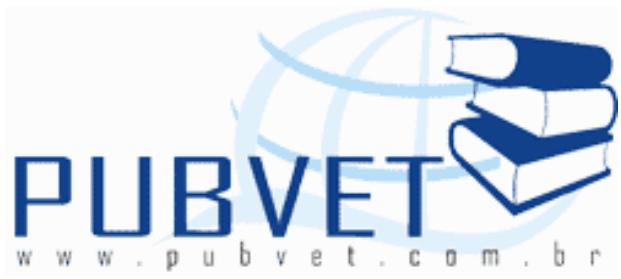

PUBVET, Publicações em Medicina Veterinária e Zootecnia.

\title{
Músculos da face lateral e medial da pelve e da coxa de Coendou prehensilis (Linnaeus, 1758) (Rodentia, Erethizontidae)
}

André Luiz Quagliatto Santos ${ }^{1}$, Saulo Fernandes Mano de Carvalho ${ }^{1}$, Lorena Tannús Menezes ${ }^{2}$, Liliane Rangel Nascimento ${ }^{2}$, Árthur Paulino Sanzo Kaminishi ${ }^{2}$ Laboratório de Ensino e Pesquisa em Animais Silvestres - LAPAS, FAMEV/UFU, e-mail: quagliatto@famev.ufu.br 1. Docentes. 2. Mestrandos.

\section{Resumo}

O propósito da pesquisa foi estudar os músculos da face lateral e medial da pelve e da coxa de Coendou prehensilis utilizando quatro exemplares adultos que foram encaminhados ao Laboratório de Ensino e Pesquisa em Animais Silvestres. Os animais tiveram a artéria aorta torácica canalizada e preenchida com solução corada de Neoprene Látex "450" @. A veia jugular também foi canalizada e preenchida com solução de formol a 10\%. Os membros pélvicos foram dissecados de modo a identificar a musculatura do membro pelvino, procurando descrever morfologicamente os músculos destas peças. No sentido crânio-lateral, os músculos laterais superficiais são: tensor da fáscia lata, reto femoral, vasto lateral, partes cranial e caudal do bíceps femoral, semitendíneo e dorsalmente a fáscia toracolombar e sua continuação em glúteo superficial; e os músculos mediais superficiais são: vasto medial, sartório e grácil. No sentido crânio-caudal, os músculos laterais profundos da pelve e da coxa são: 
SANTOS, A.L.Q. et al. Músculos da face lateral e medial da pelve e da coxa de Coendou prehensilis (Linnaeus, 1758) (Rodentia, Erethizontidae). PUBVET, Londrina, V. 5, N. 20, Ed. 167, Art. 1125, 2011.

glúteo médio, glúteo profundo, gêmeos, obturador interno e quadrado femoral; e os músculos mediais profundos são: pectíneo, adutor e semimembranáceo.

Palavras-chave: anatomia, músculos, ouriço cacheiro, membros pelvinos.

\title{
Muscles of the lateral and medial face of the thigh and the pelvis of the Coendou prehensilis (Linnaeus, 1758) (Rodentia, Erethizontidae)
}

\begin{abstract}
The purpose of this research was to study the muscles of the lateral and medial face of the thigh and the pelvis of Coendou prehensilis using four adult specimens that were sent to the Laboratory for Teaching and Research on Wild Animals. The animals had their thoracic aorta channeled and filled with colored solution of Neoprene Latex "450" $($. The jugular vein was also channeled and filled with formaldehyde solution $10 \%$. Hind limbs were dissected to identify the muscles of the pelvic members, describing the morphology of the muscles of these specimens. In the cranial-lateral direction, the superficial lateral muscles are tensor fasciae latae, rectus femoris, vastus lateralis, cranial and caudal portion of the biceps femoris, semitendinosus and dorsally the thoracolumbar fascia and its continuation in gluteal superficial muscle. The superficial medial muscles are vastus medialis, sartorius and gracilis. In the craniocaudal direction, the deep lateral muscles of the pelvis and the thigh are gluteus medius, gluteus deep, gemellus, obturator internus and quadratus femoris, and the deep medial muscles are pectineus, adductor and semimembranosus.
\end{abstract}

Keywords: anatomy, muscles, porcupine, pelvic members.

\section{INTRODUÇÃO}

Entre as ordens de mamíferos Rodentia é a que se apresenta com maior número de espécies, 2052, inclusas em 468 gêneros e 29 famílias recentes (NOWAK, 1990). Este número expressivo representa aproximadamente 43\% 
SANTOS, A.L.Q. et al. Músculos da face lateral e medial da pelve e da coxa de Coendou prehensilis (Linnaeus, 1758) (Rodentia, Erethizontidae). PUBVET, Londrina, V. 5, N. 20, Ed. 167, Art. 1125, 2011.

das espécies viventes conhecidas de mamíferos recentes (WILSON e REEDER, 1993), e é elevado para 50 famílias se forem considerados os grupos extintos (LUCKETT e HARTENBERGER, 1985).

O estudo e a descrição da morfologia dos animais domésticos (DYCE, 2004; GETTY, 1986) é muito importante para a utilização de tais conhecimentos em processos cirúrgicos e atendimentos em hospitais veterinários. Quando se trata de animais silvestres, esta descrição se torna ainda mais significativa por se tratar de uma área pouco explorada e conhecida, bem como, pela importância ambiental destes animais.

Os músculos estabelecem o contorno morfológico característico de cada espécie e são os órgãos ativos do movimento (DI DIO et al., 2003). É difícil descrever o sistema muscular dos mamíferos, por causa das variações das disposições muscular nas diversas espécies (ORR, 1986). Porém a caracterização anatômica dos músculos fornece informações relevantes sobre hábitos alimentares, força e comportamento (AVERSI-FERREIRA et al., 2006).

O Coendou prehensilis é um tetrápode arborícula, e deve possuir uma musculatura que favoreça sua escalada e permanência sobre as árvores, e que assegure sua alimentação (MALANGE-MARQUES, 2009).

O sistema muscular dos mamíferos varia muito nas diferentes formas especializadas (ORR, 1986), sendo que esta especialização, no que diz respeito aos membros, tem como finalidade proporcionar uma movimentação adequada, de acordo com os hábitos destes animais (ROMER, 1985).

Tendo em vista que o Coendou prehensilis possui hábitos e movimentação característicos da espécie, objetivou-se realizar uma descrição da anatomia e morfologia dos músculos da face lateral da pelve e da coxa, bem como as origens e inserções dos mesmos, para compreensão da locomoção desse animal e uso desses conhecimentos na prática da Medicina Veterinária. 
SANTOS, A.L.Q. et al. Músculos da face lateral e medial da pelve e da coxa de Coendou prehensilis (Linnaeus, 1758) (Rodentia, Erethizontidae). PUBVET, Londrina, V. 5, N. 20, Ed. 167, Art. 1125, 2011.

\section{MATERIAL E METODOS}

Para a realização deste trabalho foram utilizados quatro exemplares adultos de Coendou prehensilis, sendo três machos e uma fêmea, procedentes do Zoológico Parque do Sabiá do município de Uberlândia, após mortes naturais. Os animais foram encaminhados ao Laboratório de Ensino e Pesquisa em Animais Silvestres (LAPAS), da Universidade Federal de Uberlândia, onde as a artéria aorta torácica foi canalizada e preenchida com solução corada de Neoprene Látex "450" ®. A veia jugular também foi canalizada e preenchida com solução de formol a $10 \%$. A seguir, o material foi fixado em solução de formol a $10 \%$ e injetado por via intramuscular profunda, subcutânea e intracavitária, permanecendo submersos nesta solução por um período mínimo de 48 horas. Para HILDEBRAND \& GOSLOW (2006), a dissecação é a técnica mais importante para o estudo dos músculos. Os membros pélvicos foram dissecados de modo a identificar a musculatura do membro pelvino,

procurando descrever os músculos da face lateral e medial da coxa destas peças.

\section{RESULTADOS E DISCUSSÃO}

Para a melhor identificação dos músculos foram individualizados. Foi observada a morfologia dos músculos, bem como suas origens e inserções, e para melhor compreensão, comparados com a literatura veterinária já existente.

GETTY (1986) descreve os músculos do membro pélvico, enfatizando, principalmente, os cães. Cita, que os músculos dos membros, especialmente os mais distais, são mais desenvolvidos no felino do que no cão, dentre outras divergências musculares. KONIG e LIEBICH (2002) e POSPEKO (1990) descrevem a miologia dos carnívoros domésticos. SCHALLER (1999), EVANS e DE LAHUNTA (1994) descrevem especialmente a musculatura do cão, enfatizando sua dissecação. 
SANTOS, A.L.Q. et al. Músculos da face lateral e medial da pelve e da coxa de Coendou prehensilis (Linnaeus, 1758) (Rodentia, Erethizontidae). PUBVET, Londrina, V. 5, N. 20, Ed. 167, Art. 1125, 2011.

Os músculos foram identificados no sentido crânio-caudal: os laterais superficiais que são: tensor da fáscia lata, reto femoral, vasto lateral, partes cranial e caudal do bíceps femoral, semitendíneo e dorsalmente a fáscia toracolombar e sua continuação em glúteo superficial; e os mediais superficiais que são: vasto medial, sartório e grácil.

O tensor da fáscia lata origina-se no túber coxal e na aponeurose do glúteo superficial, insere-se na superfície cranial da extremidade distal do fêmur. O reto femoral origina-se no trocânter maior do fêmur e insere-se na superfície cranial da extremidade distal do fêmur, estando cranial ao vasto lateral, porém eles formam um grande grupo motor. Diferentemente dos animais domésticos estes músculos são mais individualizados e segundo Hildebrand (1995), no gato o vasto lateral é cranial ao reto femoral.

O vasto lateral origina-se na face sacro-pelvina do osso ílio e na face medial da extremidade proximal do corpo do osso fêmur, e se insere na superfície lateral da extremidade distal do fêmur. A parte cranial do bíceps femoral origina-se no túber isquiádico e insere-se na face lateral da articulação do joelho. A parte caudal do bíceps femoral origina-se também no túber isquiádico e insere-se na face lateral do corpo da tíbia e fáscia superficial da superfície craniolateral da perna. O semitendíneo origina-se nos processos espinhais das primeiras vértebras caudais e insere-se na superfície craniomedial no terço médio da tíbia, caudal à inserção do bíceps femoral.

O músculo sartório, tem origem na face ventral do pube, inserindo-se na face medial da articulação do joelho. O grácil é um grande músculo da face medial superficial da coxa, ele origina-se na face ventral da sínfise pélvica e insere-se na face medial da tíbia, desde o seu terço proximal ao terço médio e com o semitendíneo também no terço médio da tíbia, em sua face medial.

Pereira et al. (2010a) estudando os músculos de coxa de Procyon cancrivorus constataram grande similaridade com os músculos da coxa dos carnívoros domésticos, como o cão e gato. Para Lima et al. (2009) e Pereira et al. (2010b) os músculos do braço, da perna e do antebraço (LIMA et al., 2010) de mão-pelada (Procyon cancrivorus), que ocorrem similarmente aos músculos 
SANTOS, A.L.Q. et al. Músculos da face lateral e medial da pelve e da coxa de Coendou prehensilis (Linnaeus, 1758) (Rodentia, Erethizontidae). PUBVET, Londrina, V. 5, N. 20, Ed. 167, Art. 1125, 2011.

dos carnívoros domésticos. Guimarães et al. (2006) descreveram o músculo abdutor crural caudal do gato doméstico. Tatu et al. (2002) estudaram os músculos femorais em humanos.

Seguindo o sentido crânio-caudal, foram identificados os músculos laterais profundos, sendo eles: glúteo médio, glúteo profundo, gêmeos, obturador interno e quadrado femoral; e os músculos mediais profundos, sendo eles: pectíneo, adutor e semimembranáceo.

O glúteo médio tem origem no túber coxal e superfície glútea do íleo, insere-se no trocânter maior do fêmur e crista sacral lateral. Já o glúteo profundo origina-se no corpo do íleo e espinha isquiádica, inserindo-se na face laterocaudal do trocânter maior do fêmur. Os músculos gêmeos originam-se na superfície lateral do ísquio, caudalmente ao acetábulo e insere-se na fossa trocantérica. O obturador interno tem origem na sínfise pélvica e superfície dorsal do ísquio e pube e insere-se na fossa trocantérica. O quadrado femoral origina-se no tuber isquiádico e insere-se na face caudal da fossa trocantérica.

O pectíneo é um pequeno músculo, quando comparado aos demais desta região, porém se comparado aos dos mamíferos domésticos, ele é relativamente mais potente. Ele tem origem na parte cranioventral do pube e sua inserção se dá em uma superfície rugosa na face medial do terço médio do fêmur. O adutor é o mais potente dos músculos mediais profundos da coxa, sua origem se dá na sínfise pélvica, inserindo-se na superfície rugosa da face medial no terço distal do fêmur. Por fim, o semimembranáceo origina-se no túber isquiádico e insere-se na face medial no terço proximal da tíbia.

Diferentemente dos animais domésticos, não foi encontrada, no Coendou prehensilis a fáscia lata. 
SANTOS, A.L.Q. et al. Músculos da face lateral e medial da pelve e da coxa de Coendou prehensilis (Linnaeus, 1758) (Rodentia, Erethizontidae). PUBVET, Londrina, V. 5, N. 20, Ed. 167, Art. 1125, 2011.

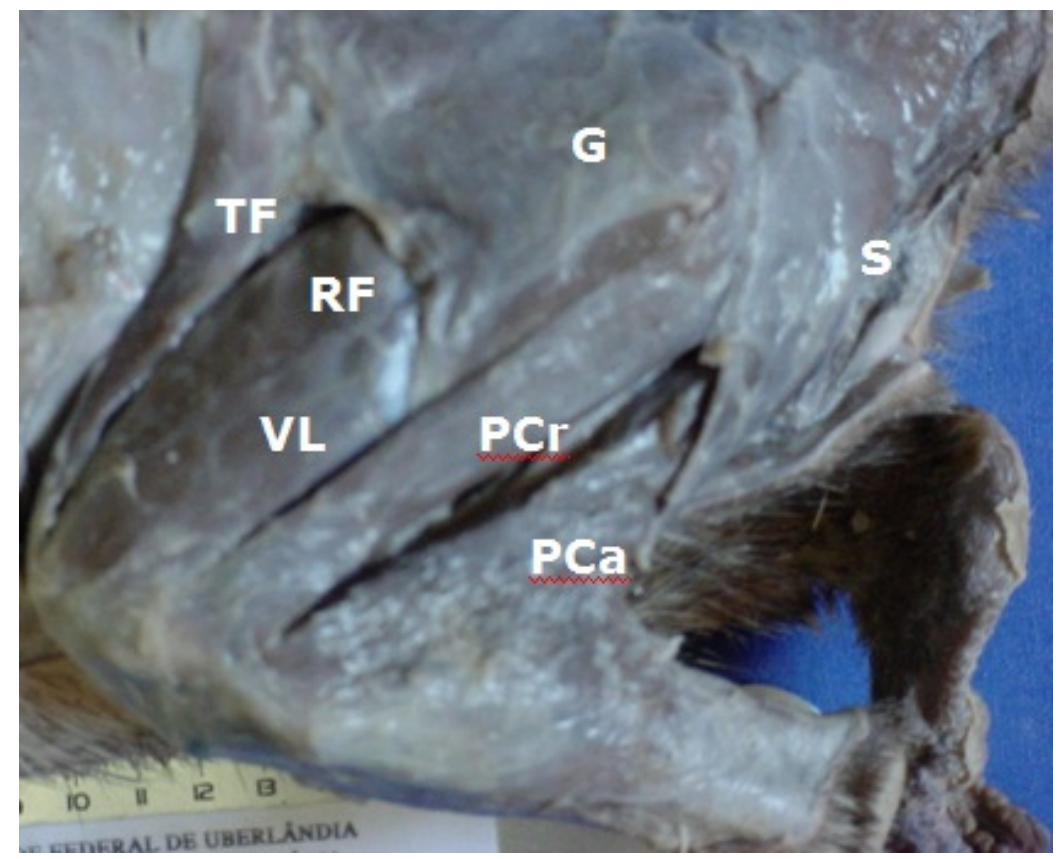

Figura1: Fotografia dos músculos superficiais da face lateral da pelve e da coxa de Coendou prehensilis. Músculo tensor da fáscia lata (TF), músculo reto femoral $(\mathrm{RF})$, vasto lateral $(\mathrm{VL})$, parte cranial do bíceps femoral $(\mathrm{PCr})$, parte caudal do bíceps femoral (Pca), semitendineo (S) e glúteo surpeficial (G). 
SANTOS, A.L.Q. et al. Músculos da face lateral e medial da pelve e da coxa de Coendou prehensilis (Linnaeus, 1758) (Rodentia, Erethizontidae). PUBVET, Londrina, V. 5, N. 20, Ed. 167, Art. 1125, 2011.

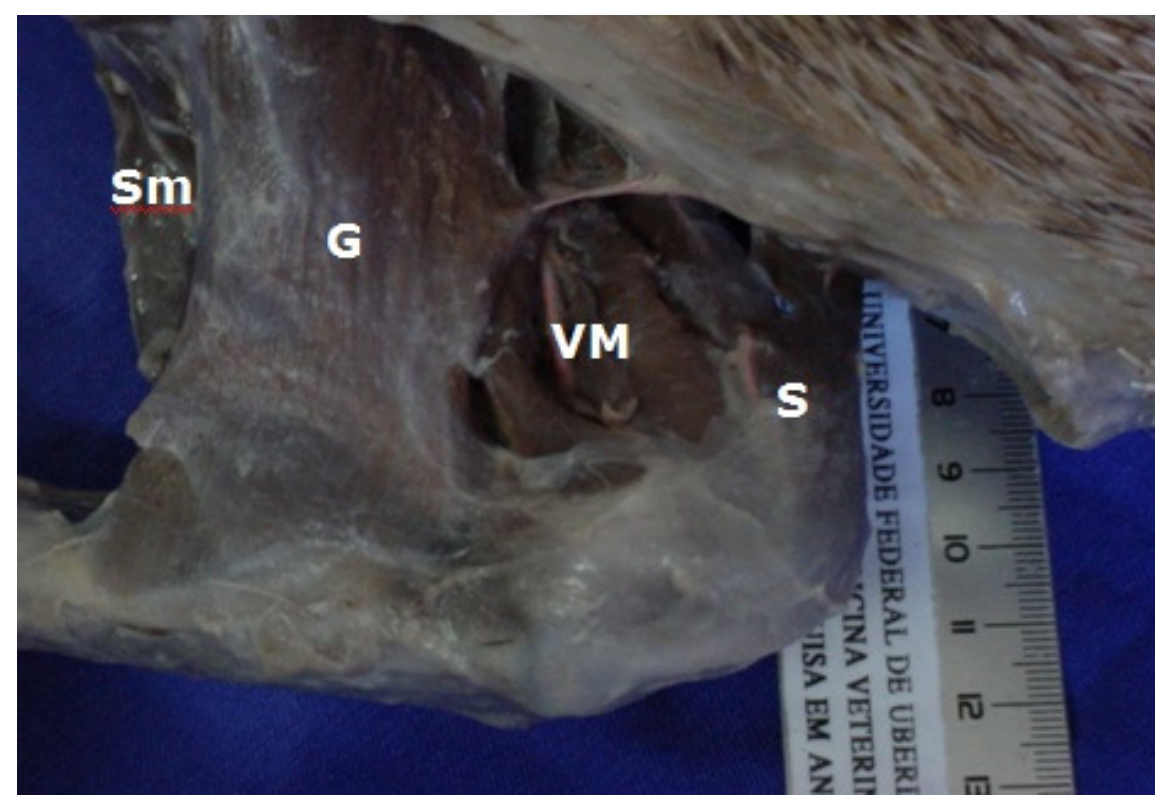

Figura 2: Fotografia dos músculos superficiais da face medial da coxa de Coendou prehensilis: músculo grácil (G), vasto medial (VM), sartório (S) e semimembranáceo (Sm).

\section{CONCLUSÃO}

Após este estudo, pode-se identificar a disposição dos músculos da face medial da coxa do Coendou prehensilis, bem como suas origens e inserções. Também se observou que de acordo com a conformação destes músculos, eles conferem a este animal uma boa capacidade de adução do membro, necessária para a vida arborícola desta espécie.

\section{REFERÊNCIAS}

AVERSI-FERREIRA, T. A.; VIEIRA, L. G.; PIRES, R. M.; SILVA, Z.; PENHA-SILVA, N. Estudo anatômico dos músculos flexores superficiais do antebraço no macaco Cebus apella. Bioscience Journal, v. 22, n. 1, p. 139-144, 2006.

DI DIO, L. J. A.; AMATUZZI, M. M.; CRICENTI, S. V. Sistema muscular. In: DI DIO, L. J. A. (Ed.). Tratado de anatomia sistêmica aplicada. São Paulo: Atheneu, 2003. p. 187-287.

DYCE, K. M., SACK, W. O., WENSING, C. J. G. Tratado de Anatomia Veterinária. 3ed. Rio de Janeiro: Editora Guanabara Koogan, 2004. 813p. 
EVANS, H. E.; de LAHUNTA, A. Guia para dissecção do cão. 3ed. Rio de Janeiro: Guanabara Koogan, 1994. p. 348.

GETTY, R. Anatomia dos Animais Domésticos. Rio de Janeiro: Guanabara Koogan, 1986, v. 2. P.1436-1441.

GUimARÃES, G. C.; MACHADO, M. R. F.; SANTOS, A. L. Q.; MIGLINO, M. A. Anatomia do músculo abdutor crural caudal do gato doméstico (Felis catus domesticus, Linnaeus 1758) Brazilian Journal of Veterinary Research Animal Sciense, São Paulo, v. 43, n. 6, p. 723727, Fev 2006.

HILDEBRAND, M.; GOSLOW, G. E. Análise da estrutura dos vertebrados. 2ed. São Paulo: Atheneu, 2006. 169p.

KÖNIG, H. E.; LIEBICH, H. G. Anatomia dos animais domésticos. São Paulo: Artmed, 2002. p. 252-263.

LIMA, V. M.; PEREIRA, F. C.; PEREIRA, K. F. Anatomia Comparativa dos músculos do Membro Torácico (Antebraço) de Mão-Pelada (Procyon cancrivorus Cuvier, 1798). In: XX Semana do Instituto de Ciências Biológicas/UFG, 2009, Goiânia. Anais da XX Semana do ICB/UFG, Nov. 2009.

LIMA, V. M.; PEREIRA, F. C.; PEREIRA, K. F. Estudo morfológico dos músculos do antebraço de mão-pelada, Procyon cancrivorus Cuvier, 1798. Bioscience Journal, Uberlândia, v. 26 n. 1, p. 109-114, Fev. 2010

LUCKETT, W. P.; HARTENBERGER, J. L. Evolutionary relationships among rodents: a multidisciplinary analysis. New York: Plenun Press, 1985. 721p.

MALANGE-MARQUES, J. Relações Filogenéticas de Rodentia: uma abordagem

comportamental. São Paulo: USP, 2009. 119p. Dissertação (Mestrado em Neurociencias e Comportamento) - Programa de Pós-graduação em Neurociencias e Comportamento, Instituto de Psicologia, Universidade de São Paulo, São Paulo, 2009.

NOWAK, R. M. Walker's Mammals of the World. 6ed. Baltimore: The Johns University Press, 1999. 1629p. v.2

PEREIRA, F. C.; LIMA, V. M.; PEREIRA, K. F. Morfologia dos músculos da coxa de mão-pelada (Procyon cancrivorus) - Cuvier 1798. Ciência Animal Brasileira , Goiânia, v. 11, n. 4, p. 947-954, out./dez. 2010a

PEREIRA, F. C.; LIMA, V. M.; PEREIRA, K. F. Descrição anatômica dos músculos da perna de Procyon cancrivorus (Cuvier 1798). Biotemas, Porto Alegre, v. 23, n. 3, p. 159-165, Out. $2010 \mathrm{~b}$

ORR, R. T. Biologia dos Vertebrados. São Paulo: Roca, 1986. 5 ed. P.185.

POPESKO, P. Atlas de anatomia topográfica dos animais domésticos. São Paulo: Manole, 1990. V.3

ROMER, A. S. PARSONS, T. S. Anatomia comparada dos vertebrados. São Paulo: Atheneu, 1985. 559p.

SCHALLER, O. Nomenclatura anatômica veterinária ilustrada. São Paulo: Manole, 1999. p. $124-129$. 
TATU, L.; PARRATTE, B.; VUILLIER, F.; DIOP, M.; MONNIER, G. Descriptive anatomy of the femoral portion of the iliopsoas muscle. Anatomical basis of medical, radiologic and surgical techniques, London, v. 23, n.6, p.371-374, Sept. 2002.

WILSON, D. E.; REEDER, D. M. Mammals species of the world: a taxonomic and geographic reference. Washington: Smithsonian Institution Press, 2005 